\title{
ECONOMIA SOLIDÁRIA E O CONTROVERSO IMPACTO DA CRISE DA CACAUICULTURA NO TERRITÓRIO LITORAL SUL DA BAHIA
}

\author{
SOLIDARY ECONOMY AND THE CONTROVERSIAL IMPACT OF THE COCOA \\ CULTURE CRISIS IN THE SOUTHERN COAST TERRITORY OF BAHIA
}

\author{
Dayvid Souza Santos ${ }^{1}$ \\ Ricardo de Araújo Kalid ${ }^{2}$ \\ Fernando Luiz Pellegrini Pessoa ${ }^{3}$ \\ Sócrates Jacobo Moquete Guzman ${ }^{4}$
}

\section{RESUMO}

Os indicadores sociais IDH e Índice de Gini são ferramentas de suma importância para realizar comparações e análises das evoluções dos fatores socioeconômicos. No Território Litoral Sul da Bahia (TLS), esses índices apontam uma melhora nas 26 cidades nas últimas duas décadas, contrariando a maior parte da literatura vigente, que apregoa a existência de uma crise prolongada. Nesse mesmo período, no TLS inúmeras experiências de produção coletivas emergiram, dando forma à economia solidária, trazendo consigo ideias de solidariedade, autogestão, entre outras. Este artigo apresenta uma análise envolvendo 147 empreendimentos econômicos solidários diagnosticados no TLS, nos quais as políticas sociais incidiram. O caráter metodológico da pesquisa é o dedutivo, com investigação de cunho descritivo e analítico. Os resultados apontam para existência de empreendimentos com baixo uso de tecnologias modernas no processo produtivo, gerando, dessa forma, pouca renda para os empreendimentos pesquisados.

Palavras-chave: desenvolvimento; economia solidária; Território Litoral Sul da Bahia.

\begin{abstract}
The IDH and Gini Social Indicators are extremely important tools for comparing and analyzing the evolution of socioeconomic factors in the Southern Coastal Territory of Bahia (TLS). These indicators indicate an improvement in the 26 cities in the last two decades, contrary to the current literature that proclaims the existence of a protracted crisis. In this same period in the TLS countless collective production experiences emerged, giving shape and solidarity economy, bringing with its ideas of solidarity, self-management among others. Moreover, this article presents an analysis involving 147 socio-economic enterprises diagnosed in the TLS where social policies substantially affect. The methodological character of the research is the deductive, with exploratory and descriptive research. The results point to enterprises with low employment of modern technologies in the productive process, generating little income so that these experiences can cope with their costs.
\end{abstract}

Keywords: development; solidarity economy; Southern Coast Territory of Bahia.

\footnotetext{
Doutorando no programa de Engenharia Industrial da UFBA - PEI/UFBA.E-mail: agrodayvid@gmail.com.

2 Doutor em Engenharia Química, professor da Universidade Federal do Sul da Bahia. E-mail: Ricardo.kalid@, gmail.com.

3 Doutor em Engenharia Química, professor do SENAI-CIMATC-BA.E-mail: fernando.pessoa@fieb.org.br.

${ }^{4}$ Doutor em Economia, professor da Universidade Estadual de Santa Cruz-BA. E-mail: socrates@uesc.br.
} 


\section{INTRODUÇÃO}

As políticas sociais no Território Litoral Sul da Bahia (TLS) produziram avanços extremamente significativos. Os números apresentados pelo Índice de Desenvolvimento Humano (IDH) e pelo Índice de Gini $^{5}$ demonstram que em duas décadas ocorreu uma evolução da renda per capita, da educação e da saúde combinada com a redução da concentração de renda na população do território (CERQUEIRA; JESUS, 2016; BAHIA, 2016). Para Dowbor (2015), os resultados desses índices são extremamente importantes para a compreensão e análise do desenvolvimento socioeconômico, uma vez que permitem medir a fraqueza e o potencial de um território em questão e auxiliar no direcionamento das políticas públicas. (BAHIA, 2016; CHACON, 2014).

Entretanto, são observadas na literatura produções científicas sobre os efeitos de uma doença conhecida como vassoura-de-bruxa ${ }^{6}$ na lavoura cacaueira, iniciada nos anos 1980 no TLS, os autores (COSTA, 2012; AGUIAR; DE MOURA PIRES, 2019; BAIARDI; TEIXEIRA, 2010; RANGEL; TONELLA, 2013; CHIAPETTI, 2014.) consideram em suas análises indicadores de desenvolvimento humano. Na maioria, os estudos publicados fazem análises baseados nas premissas do crescimento econômico, o qual valoriza o tamanho da economia com base em variações do Produto Interno Bruto (PIB) (NEVES, 2018; CHACON, 2014, p. 49), critério criticado por Dowbor (2015). Eles sustentam que esse indicador não permite uma visão sistêmica e em múltiplas dimensões, pois sua estrutura analítica é orientada para quantificar apenas a intensidade de uso dos recursos, não possibilitando a análise de informações das pequenas dinâmicas econômicas e sociais (CHACON, 2014, p. 49). São exemplo as organizações de produção e serviços de caráter coletivo, que surgiram nesse período de forma mais consolidada organizacionalmente e que Morais (2013) chama de economia solidária, definidas por ele como um fenômeno social expressivo, cujas iniciativas se baseiam nas ideias de solidariedade e antagonismo ao individualismo competitivo.

De acordo com o Plano de Desenvolvimento Territorial Sustentável Solidária (BAHIA, 2016), esses empreendimentos coletivos possibilitaram a uma parcela da população do TLS mudanças nos hábitos de produção e consumo, com valorização e preservação do meio ambiente, geração de postos de trabalho e renda e incentivo ao trabalho cooperativo e emancipador. Esses fatores, somados às políticas públicas, foram fundamentais para melhorar as informações geradas pelo IDH e pelo Índice de Gini nos últimos 20 anos, contrariando a maior parte da literatura vigente sobre o tema. Isso evidencia que a crise ficou circunscrita aos médios e grandes produtores de cacau que não conseguiram retomar a quantidade produzida até a década de 1980. De fato, esses produtores continuam com alto grau de endividamento, o que vem impossibilitando a retomada do investimento mesmo porque os custos de produção do cacau na região de Ilhéus-Itabuna para esses produtores superaram as receitas (MIRA, 2013) e continuaram assim até $2017^{7}$.

Nessa perspectiva, este artigo pretende refletir sobre a experiência de cidadãos brasileiros radicados no Território Litoral Sul da Bahia que buscaram outro modelo de desenvolvimento para superar os desafios gerados pela monocultura do cacau. Nesse percurso analítico-descritivo,

${ }^{5}$ É um instrumento criado pelo matemático italiano Conrado Gini, usado para medir o grau de concentração de renda. Nesse contexto, ele aponta a diferença entre os rendimentos dos mais pobres e dos mais ricos. Numericamente, varia de 0 a 1 , sendo 0 - Sem concentração e 1 - Completo concentração. O coeficiente de Gini pode ser calculado por meio da Fórmula de Brown (DATASUS, 2010) (DESIGUALDADE SOCIAL, 2018).

${ }^{6}$ Sua denominação científica é Crinipellis perniciosa e tem como agente causal o fungo Moniliophtora perniciosa, que provoca principalmente inchação, superbrotamento nos cacaueiros e sua morte (CEPLAC, 2017).

7 Sobre esse assunto, ver artigo "Cacau: Custos de produção passam de R \$ 106 por arroba", disponível em: http:// mercadodocacau.com/artigo/cacau-custos-de-producao-passam-de-r-106-por-arroba. Acesso em: 27 maio 2020. 
pode-se perceber que muitas experiências da economia solidária no território em questão são desenvolvidas com suas peculiaridades.

Nesse sentido, este artigo está estruturado da seguinte forma: uma análise da realidade socioeconômica com base em dados do IDH e do Índice de Gini do TLS da Bahia; na segunda seção, pretende-se apresentar o surgimento da economia solidária no território e sua interface com as políticas públicas de desenvolvimento territorial; no terceiro momento é apresentada a metodologia utilizada para a construção da análise dos empreendimentos; já a quarta seção se refere à interpretação dos dados concernentes à pesquisa realizada nos 147 empreendimentos econômicos solidários diagnosticados no TLS, principalmente com as definições referenciadas que dão suporte teórico a esta abordagem; por fim, na quinta seção, são apresentadas algumas considerações elaboradas com base nos dados coletados e analisados.

\section{ANÁLISE DO COMPORTAMENTO DO ÍNDICE DE GINI E DO IDH DO TLS}

O Território Litoral Sul da Bahia (TLS) foi criado por meio do projeto de lei n. ${ }^{\circ} 12.638$, de 10 de janeiro de 2013, e abrange uma área de aproximadamente $15 \mathrm{mil} \mathrm{km}^{2}$, o que corresponde a 2,6\% do território estadual, sendo que 26 municípios compõem este território (BAHIA, 2016). Nessa região, a falência dos grandes produtores de cacau, provocada pela infestação da praga vassoura-de-bruxa, possibilitou a desestruturação do poder político dos "coronéis", que se utilizavam de modos de produção quase escravocratas. Esse fator impactou diretamente as médias e grandes propriedades, que diminuíram significativamente sua produção (COSTA, 2012).

Porém, a tese de que os municípios do TLS vivem uma estagnação econômica desde o início da década de 1990 até a atualidade como reflexo da crise do cacau na microrregião Ilhéus-Itabuna e em grande parte da mesorregião do Sul Baiano não parece se sustentar. De fato, embora abrangendo um período um pouco menor, Mira (2013) calcula que

Entre os anos comparados (2009-1999), o IPCA teve uma variação acumulada da ordem de $90 \%$ enquanto o PIB dos municípios da microrregião Ilhéus-Itabuna cresceram, em média, 214\%. Estes resultados, inclusive, se repetem em toda a mesorregião sulbaiano. (MIRA, 2013, p. 85).

Como a economia depende da produção do cacau em amêndoas para garantir a subsistência da população, ex-trabalhadores rurais adquiriram, por meio da reforma agrária, 142 mil hectares de terra dos antigos proprietários que detinham áreas acima de 300 hectares (BAHIA, 2016; BRASIL, 2015a). Esse acontecimento possibilitou uma desconcentração fundiária no TLS, redistribuindo a terra entre os que atuam na cadeia do cacau, segundo o Instituto Brasileiro de Geografia e Estatística (IBGE, 2006), da seguinte forma: pequenos estabelecimentos rurais (de 10 a 50 hectares), representando $37 \%$ dos imóveis rurais, seguidos dos minifúndios (com área menor do que o módulo fiscal regional de 20 hectares), com 27\% dos estabelecimentos rurais.

Com a produção de aproximadamente 40 mil toneladas de cacau em amêndoas por ano, 64\% destas oriundas de pequenas propriedades (SIDRA, 2018; SILVA et al, 2017), os empreendimentos familiares pugnaram por rearticular o comércio de cacau do TLS. De fato, até chegar a ser comercializado o produto sofre beneficiamento nas áreas rurais (quebra, fermentação e secagem das amêndoas) (UNCTAD, 2016) e é vendido para atravessadores, que o comercializa para as indústrias moageiras. 
Nas moageiras, a amêndoa seca pode seguir dois caminhos: 1) a indústria de confeitaria ou 2) a indústria de alimentos. Trilhando a primeira rota, a amêndoa vai para a indústria de confeitaria, em seguida para o mercado varejista e daí ao consumidor final. Pela segunda rota, a amêndoa passa pela indústria de confeitaria, de fármacos e tabacos antes de ir ao varejo, até chegar à última etapa, que é o consumo final (COUTO, 2011), conforme Figura 1.

Dentre os produtos intermediários que podem ser obtidos do processamento do cacau destacam-se quatro: o liquor, a manteiga, o cake e o pó de cacau (UNCTAD, 2016).

\section{FIGURA 1 - PROCESSAMENTO DAS AMÊNDOAS DE CACAU ATÉ A FABRICAÇÃO DO CHOCOLATE}

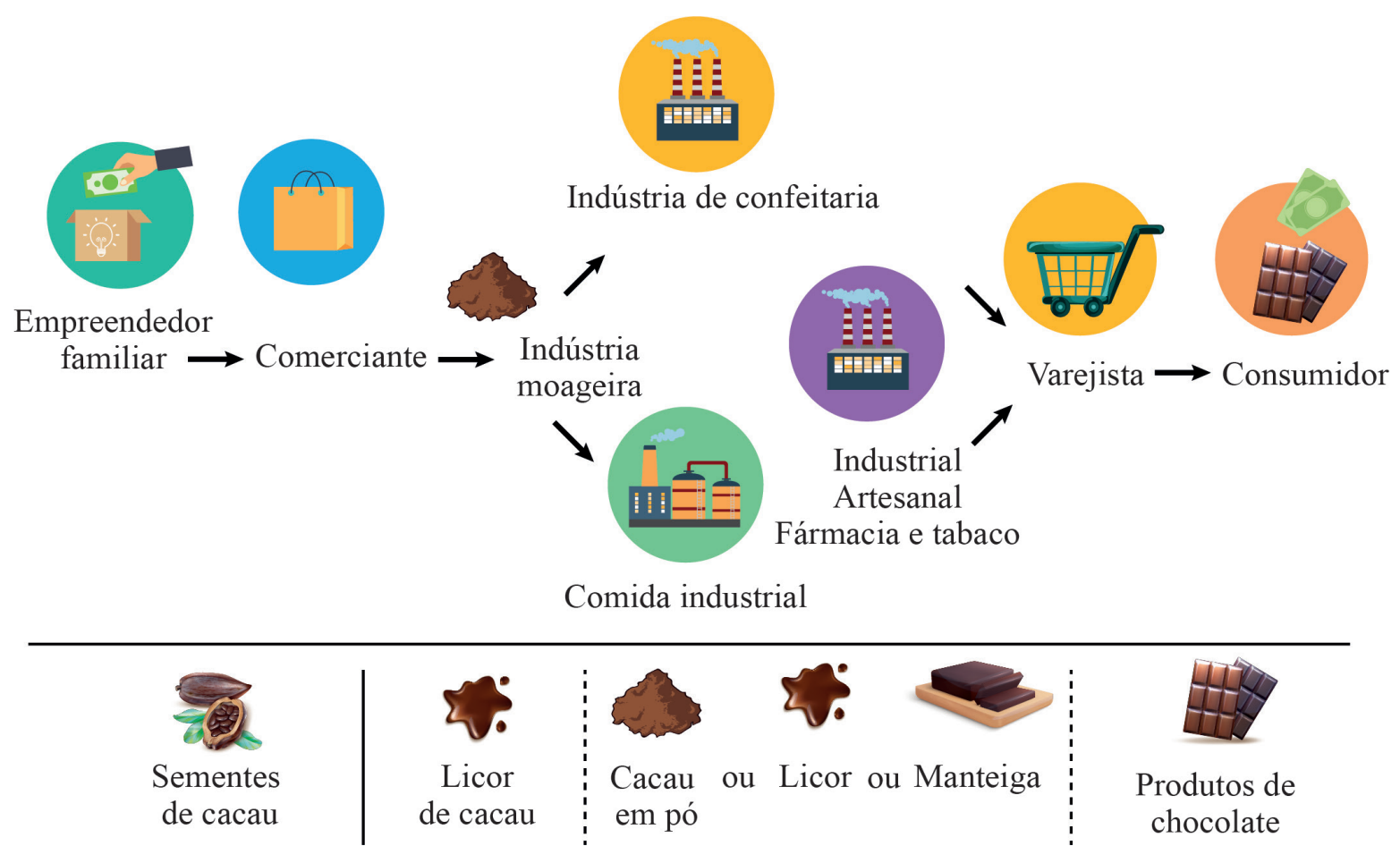

Fonte: Couto (2011).

Simultaneamente, ocorreu uma diversificação da produção do TLS no período de 1990 a 2009, a exemplo da produção de banana, que saltou de 30 toneladas mil para 31 mil; de coco, que aumentou de sete mil toneladas para 42 mil, e de café, que obteve uma ampliação de mil toneladas para seis mil (CERQUEIRA; JESUS, 2016). Entre os empreendedores familiares do TLS, o comércio predominante é o da amêndoa de cacau (SILVA et al., 2015). Esse produto tem uma demanda significativa na indústria de chocolates e derivados, porém tem baixo valor agregado (COUTO, 2011; FONTES, 2013; SILVA et al., 2015). Mas, mesmo com pouca agregação de valor, o fato de a terra e a renda estarem melhor distribuídas tem reflexo positivo no TLS.

Recentemente, empreendimentos solidários têm se esforçado para produzir chocolate, bebidas e outros derivados do cacau. Essas iniciativas segundo Prezotto apud Lima e Wilkinson (2002), agregam valor ao produto, aumentam a renda do produtor e ampliam a arrecadação de impostos por parte do estado e de municípios. 
No entanto Silva e Carneiro (2014) pontuam que os empreendedores solidários têm as mesmas dificuldades que as pequenas empresas, já que suas estruturas produtivas são similares, com baixo padrão tecnológico, com pequena escala de produção, sem dispor de condições financeiras para modernização, além de dependerem de atravessadores, salvo algumas exceções. No TLS, esses empreendimentos apresentam grande diversidade, contendo experiências com alto grau de precariedade e outras mais estruturadas.

Um exemplo de empreendimento mais bem estruturado é a Cooperativa de Desenvolvimento Sustentável da Agricultura Familiar do Sul da Bahia (Coofasulba), que conta com 42 associações a ela vinculadas e 298 agricultores cooperados. Esse empreendimento realizou transações comerciais entre 2006 a 2015 no valor de R\$ 3,7 milhões de reais, conforme Tabela 1, exclusivamente para o Programa de Aquisição de Alimentos (PAA), criado em 2 de julho de 2003 pelo Governo Federal (SANTANA, 2013; BRASIL, 2003). A cooperativa destinou seus produtos para aproximadamente 31 instituições do TLS, e mais de 400 famílias receberam seus kits (cesta com produtos agrícolas produzidos pelos associados) quinzenalmente (CEPLAC, 2013). Apesar de ser uma iniciativa positiva que deve ser mantida, os produtos comercializados têm baixo valor agregado, pois são alimentos in natura ou com beneficiamento primário.

\section{TABELA 1 - VALORES COMERCIALIZADOS PELA COOFASULBA POR MEIO DO} PROGRAMA DE AQUISIÇÃO DE ALIMENTOS (PAA)

\begin{tabular}{cc}
\hline ANO & VALOR / (R\$) \\
\hline 2006 & 80504,50 \\
\hline 2007 & 291536,28 \\
\hline 2008 & 510263,04 \\
\hline 2009 & 556549,30 \\
\hline 2010 & - \\
\hline 2011 & 229449,00 \\
\hline 2012 & 1091800,00 \\
\hline 2013 & - \\
\hline 2014 & - \\
\hline 2015 & 910610,03 \\
\hline
\end{tabular}

Fonte: Elaboração própria, com base em Conab (2015) e Santana (2013).

Outra situação pode ser observada na Cooperativa de Produção Agropecuária Construindo o Sul (Cooprasul), situada no assentamento Terra Vista, município de Arataca/BA, que transforma $60 \%$ das frutas em polpa e $40 \%$ em doces e geleias para o consumo das famílias cooperadas e para venda externa. Desses produtos, $40 \%$ são comercializados por meio do PAA (CAMPOS et. al. 2018). Apesar de a cooperativa buscar industrializar os frutos, a produção ainda não é economicamente significativa para modificar o perfil produtivo de produtos de baixo valor agregado no TLS. 
Dessa forma, apesar da dita "crise cacaueira", Rangel e Tonella (2013) explicitam que as políticas sociais funcionaram como uma resposta a favor da inclusão social, com observáveis melhorias nas condições de vida da população do TLS. A Figura 2 mostra dados do IDH ${ }^{8}$, de acordo com o qual todos os municípios do TLS melhoraram seu índice.

FIGURA 2 - ÍNDICE DE DESENVOLVIMENTO HUMANO DO TLS (2000-2010)



Fonte: BRASIL, 2015a.

Na Tabela 2, é possível observar que no período 1991-2010 o IDH desses municípios aumentou, como em Barro Preto (de 0,226 para 0,662), Mascote (de 0,208 para 0,581) e Maraú (de 0,224 para 0,593). Isso representa uma variação de 166\%,179\% e 143\%, respectivamente. Esses foram os três municípios que apresentaram as maiores variações de IDH. Já o município de Floresta Azul apresentou a menor variação dentre os municípios avaliados, com exceção do período 1991-2000, em que a cidade de Coaraci expressou a menor variação.

A cidade de Itabuna, apesar de ter apresentado a menor variação do IDH, ou seja, 57\% no período 1991-2010, obteve o melhor índice entre os municípios nos respectivos censos, com IDH de 0,453, 0,581 e 0,712, ficando com o melhor IDH entre as cidades do TLS no período estudado. A cidade de Ilhéus também apresentou significativo aumento nos decênios estudados, com crescimento no IDH de 0,389 para 0,521, alcançando 0,690 nos respectivos períodos censitários de 1991, 2000 e 2010 e mantendo-se em segundo lugar em todos os anos. Em relação à variação, a cidade de Ilhéus obteve a quinta menor variação, com $77 \%$ no período 2010-1991 (BAHIA, 2015).

\footnotetext{
8 O Índice de Desenvolvimento Humano (IDH) é uma medida resumida do progresso em longo prazo de três dimensões básicas do desenvolvimento humano: renda, educação e saúde. Seu cálculo é feito inferindo a média geométrica dos três índices das respectivas dimensões, ou seja, seu valor resulta da seguinte fórmula: $\mathrm{IDH}=\sqrt[3]{\left(\mathrm{I}_{\text {Vida }} \times \mathrm{I}_{\text {Educação }} \times \mathrm{I}_{\text {Rendimento }}\right)}($ PNUD, 2013, 2018).
} 
TABELA 2 - ÍNDICE DE DESENVOLVIMENTO HUMANO DOS MUNICÍPIOS DO TLS DA BAHIA EM 1991, 2000 E 2010

\begin{tabular}{|c|c|c|c|c|c|c|c|c|c|}
\hline \multirow[t]{2}{*}{ Município } & \multicolumn{3}{|c|}{ Anos } & \multicolumn{3}{|c|}{$\begin{array}{l}\text { Variação do IDH entre } \\
\text { anos }\end{array}$} & \multicolumn{3}{|c|}{$\begin{array}{c}\text { Posição do município em } \\
\text { relação a } \\
\text { variação do IDH } \\
\end{array}$} \\
\hline & 1991 & 2000 & 2010 & $\begin{array}{c}2000 \text { a } \\
1991\end{array}$ & $\begin{array}{c}2010 \mathrm{a} \\
2000\end{array}$ & $\begin{array}{c}2010 \text { a } \\
1991\end{array}$ & $\begin{array}{c}2000 \text { a } \\
1991\end{array}$ & $\begin{array}{c}2010 \mathrm{a} \\
2000\end{array}$ & $\begin{array}{c}2010 \mathrm{a} \\
1991\end{array}$ \\
\hline Barro Preto & 0,226 & 0,421 & 0,602 & 0,195 & 0,181 & 0,376 & 1 & 10 & 1 \\
\hline Mascote & 0,208 & 0,356 & 0,581 & 0,148 & 0,225 & 0,373 & 5 & 2 & 2 \\
\hline Maraú & 0,244 & 0,354 & 0,593 & 0,110 & 0,239 & 0,349 & 22 & 1 & 3 \\
\hline Uruçuca & 0,269 & 0,438 & 0,616 & 0,169 & 0,178 & 0,347 & 3 & 13 & 4 \\
\hline Itacaré & 0,241 & 0,384 & 0,583 & 0,143 & 0,199 & 0,342 & 7 & 4 & 5 \\
\hline Itapé & 0,263 & 0,448 & 0,599 & 0,185 & 0,151 & 0,336 & 2 & 20 & 6 \\
\hline Pau-Brasil & 0,259 & 0,401 & 0,583 & 0,142 & 0,182 & 0,324 & 8 & 9 & 7 \\
\hline Itaju do Colônia & 0,270 & 0,431 & 0,592 & 0,161 & 0,161 & 0,322 & 4 & 18 & 8 \\
\hline Arataca & 0,247 & 0,372 & 0,559 & 0,125 & 0,187 & 0,312 & 14 & 7 & 9 \\
\hline Santa Luzia & 0,249 & 0,378 & 0,556 & 0,129 & 0,178 & 0,307 & 10 & 12 & 10 \\
\hline Aurelino Leal & 0,263 & 0,365 & 0,568 & 0,102 & 0,203 & 0,305 & 25 & 3 & 11 \\
\hline Buerarema & 0,309 & 0,420 & 0,613 & 0,111 & 0,193 & 0,304 & 21 & 6 & 12 \\
\hline Almadina & 0,261 & 0,405 & 0,563 & 0,144 & 0,158 & 0,302 & 6 & 19 & 13 \\
\hline Una & 0,259 & 0,366 & 0,560 & 0,107 & 0,194 & 0,301 & 24 & 5 & 14 \\
\hline Ilhéus & 0,389 & 0,521 & 0,690 & 0,132 & 0,169 & 0,301 & 9 & 16 & 15 \\
\hline São José da Vitória & 0,246 & 0,361 & 0,546 & 0,115 & 0,185 & 0,300 & 18 & 8 & 16 \\
\hline Ubaitaba & 0,316 & 0,434 & 0,611 & 0,118 & 0,177 & 0,295 & 17 & 14 & 17 \\
\hline Ibicaraí & 0,334 & 0,449 & 0,625 & 0,115 & 0,176 & 0,291 & 19 & 15 & 18 \\
\hline Bahia & 0,386 & 0,512 & 0,660 & 0,126 & 0,148 & 0,274 & 13 & 22 & 19 \\
\hline Canavieiras & 0,318 & 0,439 & 0,590 & 0,121 & 0,151 & 0,272 & 16 & 21 & 20 \\
\hline Jussari & 0,299 & 0,426 & 0,567 & 0,127 & 0,141 & 0,268 & 12 & 24 & 21 \\
\hline Camacã & 0,316 & 0,441 & 0,581 & 0,125 & 0,140 & 0,265 & 15 & 25 & 22 \\
\hline Itajuípe & 0,338 & 0,451 & 0,599 & 0,113 & 0,148 & 0,261 & 20 & 23 & 23 \\
\hline Coaraci & 0,354 & 0,433 & 0,613 & 0,079 & 0,180 & 0,259 & 27 & 11 & 24 \\
\hline Itabuna & 0,453 & 0,581 & 0,712 & 0,128 & 0,131 & 0,259 & 11 & 26 & 25 \\
\hline Itapitanga & 0,325 & 0,409 & 0,571 & 0,084 & 0,162 & 0,246 & 26 & 17 & 26 \\
\hline Floresta Azul & 0,347 & 0,454 & 0,557 & 0,107 & 0,103 & 0,210 & 23 & 27 & 27 \\
\hline
\end{tabular}

Fonte: ATLAS DO DESENVOVIMENTO HUMANO NO BRASIL, 2013.

Na Figura 3 e na Tabela 3, a seguir, é possível observar o progresso de alguns municípios do TLS da Bahia, avaliado com base no Índice de Gini, entre os anos de 1991 e 2010 . Na maioria dos municípios do TLS melhorou a distribuição de renda, comprovada pela diminuição da média do Índice de Gini. A quantidade de municípios que teve uma melhora distribuição de 
uma avaliação da outra também foi sempre acima dos 60\%. Ou seja, no TLS o Índice de Gini diminuiu, pois houve melhor distribuição de renda na região.

A melhor distribuição de renda entre 1991 e 2010 pode ser atribuída às políticas sociais implementadas no país, as quais ajudaram as populações mais carentes a obterem algum tipo de renda, a exemplo do Programa Bolsa Família, do Governo Federal, que em 2011 beneficiou cerca $18 \%$ da população total da microrregião Ilhéus/Itabuna, ou 141 mil pessoas (IPEADATA, 2012). Além disso, o Programa Nacional de Fortalecimento da Agricultura Familiar (Pronaf) concedeu aproximadamente 106 milhões de reais em financiamentos para a pecuária e a agricultura familiar no território (BCB, 2012), e em 2010 a Previdência Social concedeu ao TLS 109 mil benefícios: uma média de 4.2 mil benefícios por município, totalizando R $\$ 803$ milhões por ano (RIBEIRO et al., 2018).

Em face desses fatos, o discurso disseminado no TLS de que existe uma crise, estagnada ou crescente desde os piores cenários com a praga vassoura-de-bruxa, é inconsistente. O lucro dos médios e grandes produtores do cacau do TLS diminuiu, mas os indicadores sociais (IDH e Índice de Gini) da região melhoraram, ou seja, se há uma crise ela ocorre na parcela da sociedade proprietária de grandes extensões de terra, uma vez que no restante da população houve avanços sociais significativos.

FIGURA 3 - ÍNDICE DE GINI TLS (2000-2010)

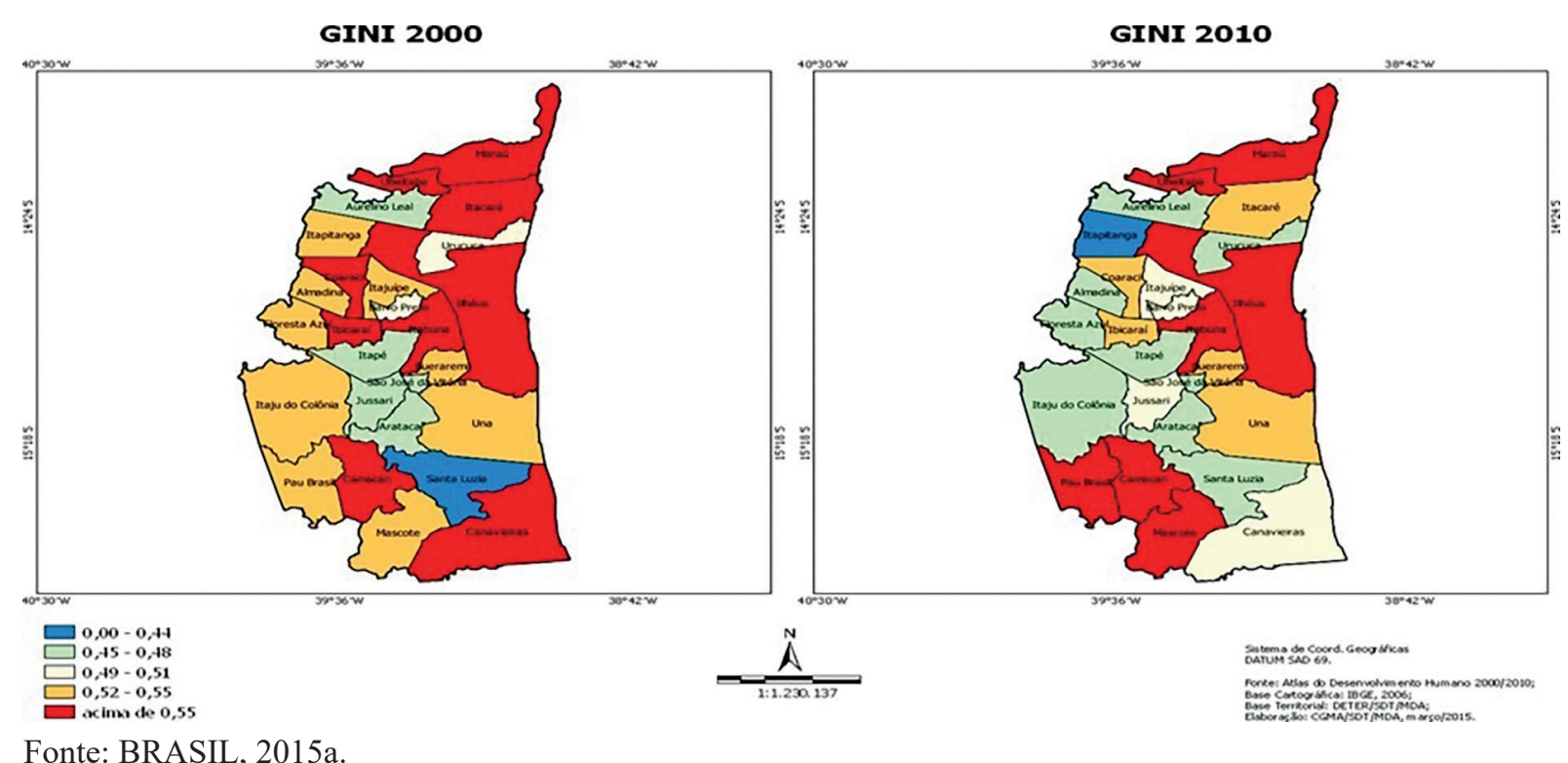

TABELA 3 - ÍNDICE DE GINI DO RENDIMENTO MÉDIO MENSAL DOMICILIAR PER CAPITA NOS MUNICÍPIOS DO TLS

\begin{tabular}{lcccccc}
\hline \multirow{2}{*}{$\begin{array}{c}\text { MUNICÍPIOS } \\
\text { TLS }\end{array}$} & \multicolumn{3}{c}{ Índice Gini dos anos } & \multicolumn{4}{c}{ Variação } \\
\cline { 2 - 7 } & $\mathbf{1 9 9 1}$ & $\mathbf{2 0 0 0}$ & $\mathbf{2 0 1 0}$ & $\mathbf{2 0 0 0}$ a 1991 & $\mathbf{2 0 1 0}$ a 2000 & $\mathbf{2 0 1 0}$ a 1991 \\
\hline Almadina & 0,514 & 0,520 & 0,534 & 0,006 & 0,014 & 0,020 \\
\hline Arataca & 0,510 & 0,479 & 0,526 & $-0,031$ & 0,047 & 0,016 \\
\hline Aurelino Leal & 0,547 & 0,502 & 0,533 & $-0,045$ & 0,031 & $-0,014$ \\
\hline Barro Preto & 0,441 & 0,496 & 0,513 & 0,055 & 0,017 & 0,072 \\
\hline
\end{tabular}




\begin{tabular}{|c|c|c|c|c|c|c|}
\hline \multirow{2}{*}{$\begin{array}{l}\text { MUNICÍPIOS } \\
\text { TLS }\end{array}$} & \multicolumn{3}{|c|}{ Índice Gini dos anos } & \multicolumn{3}{|c|}{ Variação } \\
\hline & 1991 & 2000 & 2010 & 2000 a 1991 & 2010 a 2000 & 2010 a 1991 \\
\hline Buerarema & 0,605 & 0,545 & 0,524 & $-0,060$ & $-0,021$ & $-0,081$ \\
\hline Camacan & 0,694 & 0,627 & 0,566 & $-0,067$ & $-0,061$ & $-0,128$ \\
\hline Canavieiras & 0,560 & 0,603 & 0,490 & 0,043 & $-0,113$ & $-0,070$ \\
\hline Coaraci & 0,626 & 0,598 & 0,548 & $-0,028$ & $-0,050$ & $-0,078$ \\
\hline Floresta Azul & 0,562 & 0,549 & 0,469 & $-0,013$ & $-0,080$ & $-0,093$ \\
\hline Ibicaraí & 0,638 & 0,615 & 0,549 & $-0,023$ & $-0,066$ & $-0,089$ \\
\hline Ilhéus & 0,641 & 0,642 & 0,589 & 0,001 & $-0,053$ & $-0,052$ \\
\hline Itabuna & 0,698 & 0,628 & 0,576 & $-0,070$ & $-0,052$ & $-0,122$ \\
\hline Itacaré & 0,628 & 0,612 & 0,556 & $-0,016$ & $-0,056$ & $-0,072$ \\
\hline Itaju do Colônia & 0,496 & 0,551 & 0,483 & 0,055 & $-0,068$ & $-0,013$ \\
\hline Itajuípe & 0,615 & 0,576 & 0,507 & $-0,039$ & $-0,069$ & $-0,108$ \\
\hline Itapé & 0,537 & 0,478 & 0,480 & $-0,059$ & 0,002 & $-0,057$ \\
\hline Itapitanga & 0,625 & 0,555 & 0,445 & $-0,070$ & $-0,110$ & $-0,180$ \\
\hline Jussari & 0,488 & 0,478 & 0,526 & $-0,010$ & 0,048 & 0,038 \\
\hline Maraú & 0,621 & 0,703 & 0,728 & 0,082 & 0,025 & 0,107 \\
\hline Mascote & 0,577 & 0,553 & 0,605 & $-0,024$ & 0,052 & 0,028 \\
\hline Pau-Brasil & 0,535 & 0,560 & 0,569 & 0,025 & 0,009 & 0,034 \\
\hline Santa Luzia & 0,520 & 0,427 & 0,500 & $-0,093$ & 0,073 & $-0,020$ \\
\hline $\begin{array}{l}\text { São José da } \\
\text { Vitória }\end{array}$ & 0,465 & 0,475 & 0,461 & 0,010 & $-0,014$ & $-0,004$ \\
\hline Ubaitaba & 0,655 & 0,571 & 0,564 & $-0,084$ & $-0,007$ & $-0,091$ \\
\hline Una & 0,532 & 0,567 & 0,519 & 0,035 & $-0,048$ & $-0,013$ \\
\hline Uruçuca & 0,517 & 0,515 & 0,494 & $-0,002$ & $-0,021$ & $-0,023$ \\
\hline Média & 0,571 & 0,555 & 0,533 & $-0,016$ & $-0,022$ & $-0,038$ \\
\hline \multicolumn{4}{|c|}{ Decréscimo médio nos quais o ínidice Gini diminuiu } & $-0,043$ & $-0,056$ & $-0,069$ \\
\hline \multicolumn{4}{|c|}{$\begin{array}{l}\text { Quantidade de municípios do TLS nos quais o índice Gini } \\
\text { diminuiu }\end{array}$} & 17 & 16 & 19 \\
\hline \multicolumn{4}{|c|}{$\begin{array}{l}\text { Quantidade relativa de municípios do TLS nos quais o índice } \\
\text { Gini diminuiu /\% }\end{array}$} & 65 & 62 & 73 \\
\hline \multicolumn{4}{|c|}{ Acréscimo médio nos quais o ínidice Gini aumentou } & 0,035 & 0,032 & 0,045 \\
\hline \multicolumn{4}{|c|}{$\begin{array}{l}\text { Quantidade de municípios do TLS nos quais o índice Gini } \\
\text { aumentou }\end{array}$} & 9 & 10 & 7 \\
\hline \multicolumn{4}{|c|}{$\begin{array}{l}\text { Quantidade relativa de municípios do TLS nos quais o índice } \\
\text { Gini aumentou / \% }\end{array}$} & 35 & 38 & 27 \\
\hline
\end{tabular}

Fonte: Elaboração própria, com base em Bahia (2016). 


\section{A ECONOMIA SOLIDÁRIA E AS POLÍTICAS SOCIAIS DO TLS}

No TLS, desde a suposta crise até a atualidade os trabalhadores buscaram construir outro modelo de desenvolvimento. Os setores mais vulneráveis socioeconomicamente do território passaram a se organizar por meio de experiências coletivas de produção, como cooperativistas, associativas, microempresas, pequenos negócios familiares, entre outros, dando origem a empreendimentos econômicos solidários (BAHIA, 2016).

Segundo Oliveira et al. (2013), essas organizações são conceitualmente consideradas como de economia solidária e emergem como uma possibilidade de geração de renda, inclusão e mudança social, nas quais o determinante é repartir os ganhos obtidos com aqueles que exercem o trabalho. Já Utting (2015) ressalta que a economia solidária tem três características fundantes: 1) os objetivos econômicos e sociais não são ambíguos; 2) envolvem graus e formas diferentes de relações de cooperação, associação e solidariedade entre trabalhadores, produtores e consumidores; e 3) praticam democracia e autogestão no local de trabalho.

Giovanni (2020) avalia que as características apresentadas por Utting (2015) permitem destacar o caráter transformador da economia solidária, porém Morais e Bacic (2019) entendem que para a economia solidária se consolidar como ecossistema inovador capaz de se emancipar e se transformar em um vetor promotor do desenvolvimento econômico e social é necessário investimento para estruturar processos tecnológicos e inovadores.

Entretanto, Lee (2019) ressalta que mesmo tendo baixa capacidade estrutural a economia solidária tem alto potencial para contribuir com o desenvolvimento local, territorial e conseguir avanços socioeconômicos.

Dessa forma, Fuini (2014) explicita que a crescente presença dessas múltiplas formas de organizações no TLS, sobretudo pela ressignificação do trabalho, foi fundamental para desencadear um processo de questionamentos do papel do Estado no planejamento e no desenvolvimento territorial.

Para Perico (2009), essas reivindicações possibilitaram a constituição de políticas públicas correspondentes às demandas sociais e o fortalecimento de processos de desenvolvimento socioeconômicos endógenos, pois os investimentos públicos feitos por meio desses instrumentos aumentaram a cobertura social do Estado no TLS, conforme explicitam Araújo (2000), Becker (2009) e Silva e Silva (2003).

Dessa forma, as políticas de promoção social desenvolvidas no TLS, conforme Figura 3, melhoraram as condições de vida da população mais carente e, consequentemente, criaram um ambiente para a subsistência de organizações econômicas, cuja base de produção é o trabalho coletivo, como mostra o IDH na Tabela 2, além de distribuir renda conforme mostra Índice de Gini na Tabela 3.

Entretanto, essas políticas se mostraram insuficientes para que ocorra um fluxo contínuo de desenvolvimento da economia solidária, já que elas não têm caráter de desenvolvimento estruturante e pouco tem contribuído para suprir as necessidades dos empreendimentos da economia solidária no TLS (BECKER; ANJOS; CALDAS, 2009), conforme Figura 4.

Por outro lado, uma vez aplicados investimentos públicos de forma a promover mudanças estruturais, espera-se que estes proporcionem um processo de engendramento civilizatório e racional, numa perspectiva de diminuir as diferenças sociais e territoriais, garantindo a sustentabilidade e menor dependência do Estado provedor, dessa forma o desenvolvimento terá uma perspectiva para além do crescimento econômico (ROCHA, 2015). 
FIGURA 4 - POLÍTICAS PÚBLICAS RECEBIDAS PELOS EES NO TLS

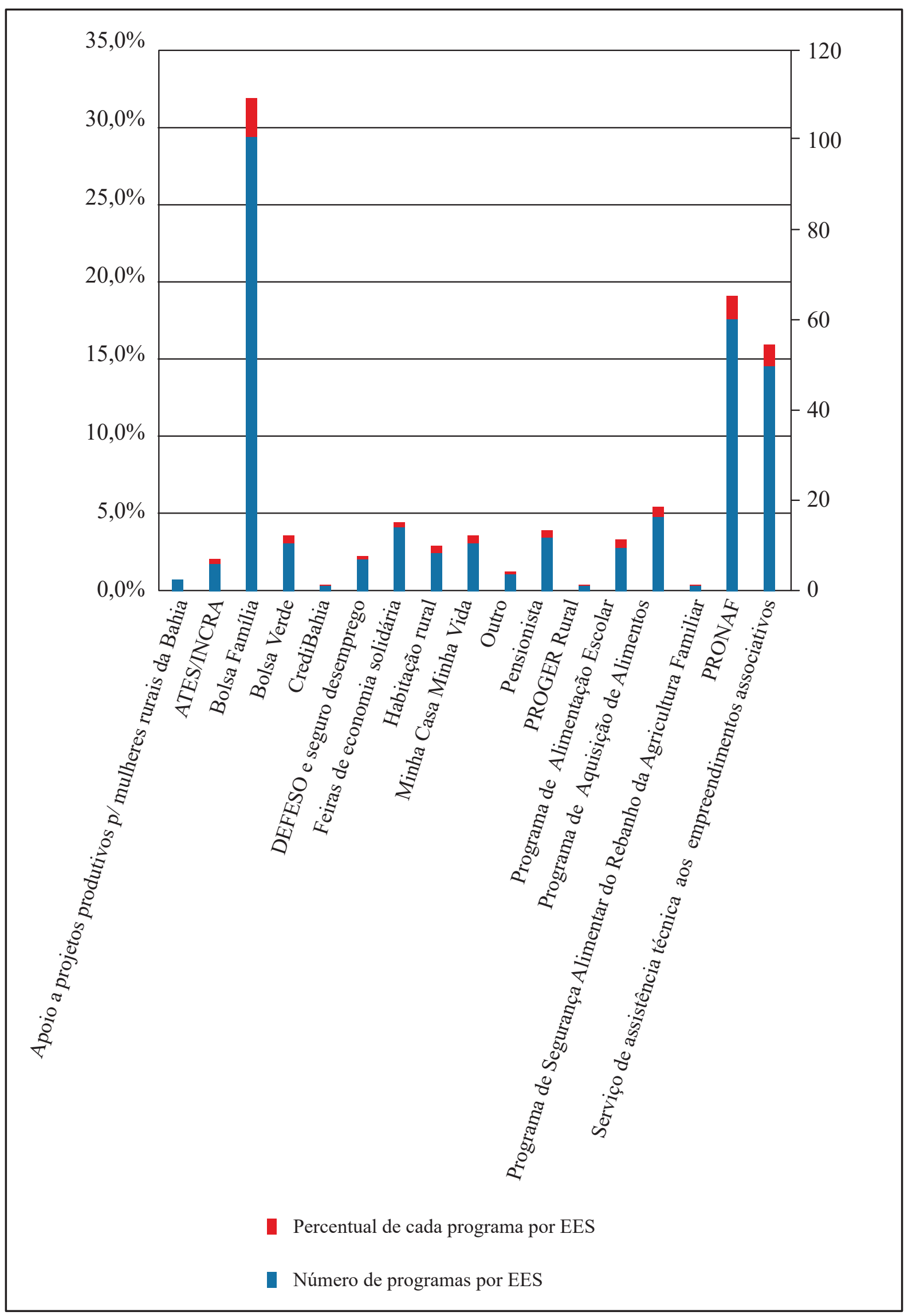

Fonte: Elaboração própria, com base em BAHIA (2017). 


\section{METODOLOGIA}

Esta pesquisa busca evidenciar com maior exatidão o que está ocorrendo no TLS da Bahia por meio da análise das características socioeconômicas dos grupos de indivíduos, bem como procura desvendar a relação entre eventos.

Para tal, o método utilizado é o dedutivo, que pressupõe a razão como única forma de chegar ao conhecimento verdadeiro, combinando meios de verificação com base em uma abordagem analítica e descritiva, de modo a entender o comportamento dos empreendimentos na realidade em que estão inseridos (GIL, 2008).

Para compreender as lacunas existentes e aprimorar o conhecimento com novas investigações, esta pesquisa utiliza técnicas de análise bibliográfica e de descrição dos fatos e fenômenos característicos da realidade, portanto, é considerada exploratória e descritiva (GIL, 2008).

Para Lakatos e Marconi (2003), quando se estabelece uma conexão da metodologia exploratória com a descritiva, possibilita-se uma narrativa na qual a compreensão dos eventos fica mais próxima da realidade.

A determinação da amostra da pesquisa, em termos qualitativos, foi obtida com base em parâmetros do Ministério do Trabalho (BRASIL, 2015b), pelos quais pertencem à economia solidária. Já a coleta de dados ocorreu por meio de pesquisa de campo realizada com base em um questionário, abrangendo questões abertas e de múltiplas respostas. Quantitativamente, a amostra pesquisada abrangeu o universo total de 100\% dos 147 empreendimentos econômicos solidários acompanhados pelo Centro Público de Economia Solidária do Litoral Sul da Bahia, nos 26 municípios do TLS da Bahia, distribuídos conforme Tabela 4.

As informações obtidas passaram por uma sistematização e organização por meio de análise descritiva e comparativa. Segundo Gerhardt e Silveira (2009), na primeira se realiza um síntese das informações e na segunda se verificam diferenças e similaridades de indivíduos. Os dados foram compiladas em um gráfico tipo radar (Figura 4) descrito por Ornstein (1989) como um procedimento original para expressar e comparar o desempenho de atividades econômicas. De acordo com os autores Rebollo (1991) e Ornstein (1989) o Gráfico Radar representa um método positivo, e por isso garante vantagens frente a outros instrumentos de análise similares, como a Matriz de Ansoff, o Gráfico BCG e o Gráfico GE/Mckinsey.

Dessa forma, por ser possível representar as inúmeras variáveis com dimensões e escalas diferentes em um único gráfico, o Radar será adotado como forma de interpretar o objetivo proposto.

TABELA 4 - QUANTIDADE DE EMPREENDIMENTOS ECONÔMICOS SOLIDÁRIOS NOS MUNICÍPIOS PESQUISADOS DO TLS

\begin{tabular}{|c|c|c|}
\hline Municípios & Quantidade & Quantidade relativa / \% \\
\hline Itapé & 2 & 1,4 \\
\hline Almadina & 1 & 0,7 \\
\hline Arataca & 1 & 0,7 \\
\hline Aurelino Leal & 3 & 2,0 \\
\hline Barro Preto & 2 & 1,4 \\
\hline
\end{tabular}




\begin{tabular}{|c|c|c|}
\hline Municípios & Quantidade & Quantidade relativa / \% \\
\hline Buerarema & 7 & 4,8 \\
\hline Camacã & 4 & 2,7 \\
\hline Canavieiras & 11 & 7,5 \\
\hline Coaraci & 3 & 2,0 \\
\hline Floresta Azul & 8 & 5,4 \\
\hline Ibicaraí & 6 & 4,1 \\
\hline Ilhéus & 15 & 10,2 \\
\hline São José da Vitória & 1 & 0,7 \\
\hline Itabuna & 22 & 15,0 \\
\hline Itacaré & 14 & 9,5 \\
\hline Itaju do Colônia & 5 & 3,4 \\
\hline Itajuípe & 4 & 2,7 \\
\hline Itapitanga & 2 & 1,4 \\
\hline Jussari & 2 & 1,4 \\
\hline Maraú & 6 & 4,1 \\
\hline Mascote & 4 & 2,7 \\
\hline Pau Brasil & 5 & 3,4 \\
\hline Santa Luzia & 5 & 3,4 \\
\hline Ubaitaba & 4 & 2,7 \\
\hline Una & 4 & 2,7 \\
\hline Uruçuca & 6 & 4,1 \\
\hline TOTAL & 147 & 100,0 \\
\hline
\end{tabular}

Fonte: Elaboração própria, com base em BAHIA (2018).

\section{RESULTADOS}

Ao dividir a análise do Gráfico Radar (Figura 5) em dois blocos de dez variáveis, é possível compreender melhor os dados. No primeiro bloco, é observado que três itens se destacam com os maiores percentuais: a formalização dos empreendimentos (84\%); a produção de matéria-prima pelos empreendimentos, (73\%) e a venda da produção (74\%).

Pode-se considerar que $84 \%$ dos empreendimentos formalizados é um número significativo, pois permite realizar parcerias com outros modelos de sociedades jurídicas, seja para pesquisa, seja para outros fins econômicos - ou não. Já os investimentos realizados pelos empreendimentos com recursos oriundos de empréstimos e fundos não reembolsáveis chegam a $12 \%$, sendo um possível limitante para o avanço econômico, científico, tecnológico e produtivo dos mesmos - contudo, foi observado que $84 \%$ dos investimentos são feitos por meio de doações dos próprios sócios ou de terceiros. 
Com relação à participação em rede, os responsáveis pelos $16 \%$ dos empreendimentos relataram ter algum envolvimento nela, demonstrando que preferem desenvolver iniciativas de cunho individual, acarretando um possível aumento de custo ao produto. Por outro lado, $74 \%$ dos EES vendem seus produtos e/ou serviços para o mercado; embora esses produtos ou serviços comercializados tenham pouco valor agregado. Por outro lado, a produção da matéria-prima realizada pelos próprios empreendimentos é significativa (60\%). Contudo, apenas 30\% dos empreendimentos conseguem remunerar seus sócios.

No bloco 2 observamos outras fragilidades, sobretudo a financeira, pois apenas 14\% dos empreendimentos pesquisados conseguem remunerar seus sócios com valores superiores a um salário mínimo. Isso é corroborado pela baixa capacidade produtiva e tecnológica. Portanto, pode-se deduzir que, apesar de seu alto percentual de comercialização e formalização, esses empreendimentos não dispõem de tecnologia para aumentar a produtividade do trabalho e contribuir no aumento de renda das famílias. Outro fator de impacto é o fato de que em apenas 5\% dos empreendimentos seus responsáveis sabem qual é a quantidade mínima a ser produzida e 5\% informarem que têm reservas para a manutenção das máquinas. Provavelmente, essa condição está vinculada também à sua baixa capacidade financeira e a sua falta de conhecimento sobre planejamento financeiro.

Com relação aos apoiadores dos empreendimentos no TLS, 12\% relataram que o Governo do Estado da Bahia está entre um dos principais. Não obstante, 49\% não informaram na etapa de coleta de dados quem os apoia. Assim, é possível entender que parte desses empreendimentos não tem nenhum tipo de apoio.

Além disso, $17 \%$ dos sócios relataram que o empreendimento funciona como um complemento de renda e não como a fonte principal. Já no tocante à comercialização, em apenas $20 \%$ dos empreendimentos os responsáveis informaram que têm facilidade de comercializar, mesmo $74 \%$ comercializando, como visto no Bloco 1. É importante ressaltar que $72 \%$ desse comércio é realizado no próprio território. Entretanto, o agravante é que, mesmo comercializando, apenas 17\% dos sócios têm algum direito social, benefícios ou garantias. Por outro lado, $57 \%$ dos sócios informaram que têm alguma experiência no ramo da atividade em execução. Contudo, é preciso combinar maior apoio institucional para aumentar a capacidade desses empreendimentos de buscar melhorias de suas condições socioeconômicas, uma vez que essas experiências são altamente dependentes dos contextos locais.

A origem desses fatores pode estar na falta de investimento de cunho estruturante, que impede os empreendimentos estudados de se modernizarem econômica, social, cultural e tecnologicamente, por isso a comercialização é feita de produtos basicamente in natura e de baixo valor agregado.

No entanto, de acordo com Lee (2019), mesmo que esses empreendimentos sejam caracterizados por pequena escala de produção e pouca tecnificação, realizam grande integração econômica e territorial com vistas a superar o desequilíbrio na distribuição da riqueza e o aumento do desemprego, por meio da organização de cooperativas, associações e outros modelos institucionais coletivos, abrindo caminhos alternativos que contribuem para os avanços sociais, conforme apresentado na Tabela 2 (IDH) e Tabela 3 (Gini).

Na Figura 5, é possível verificar a disposição dos dados que compõem as características dos EES do TLS da Bahia, em um cenário de ascensão social e econômica. 

ECONÔMICOS SOLIDÁRIOS NOS MUNICÍPIOS DO TLS PESQUISADOS

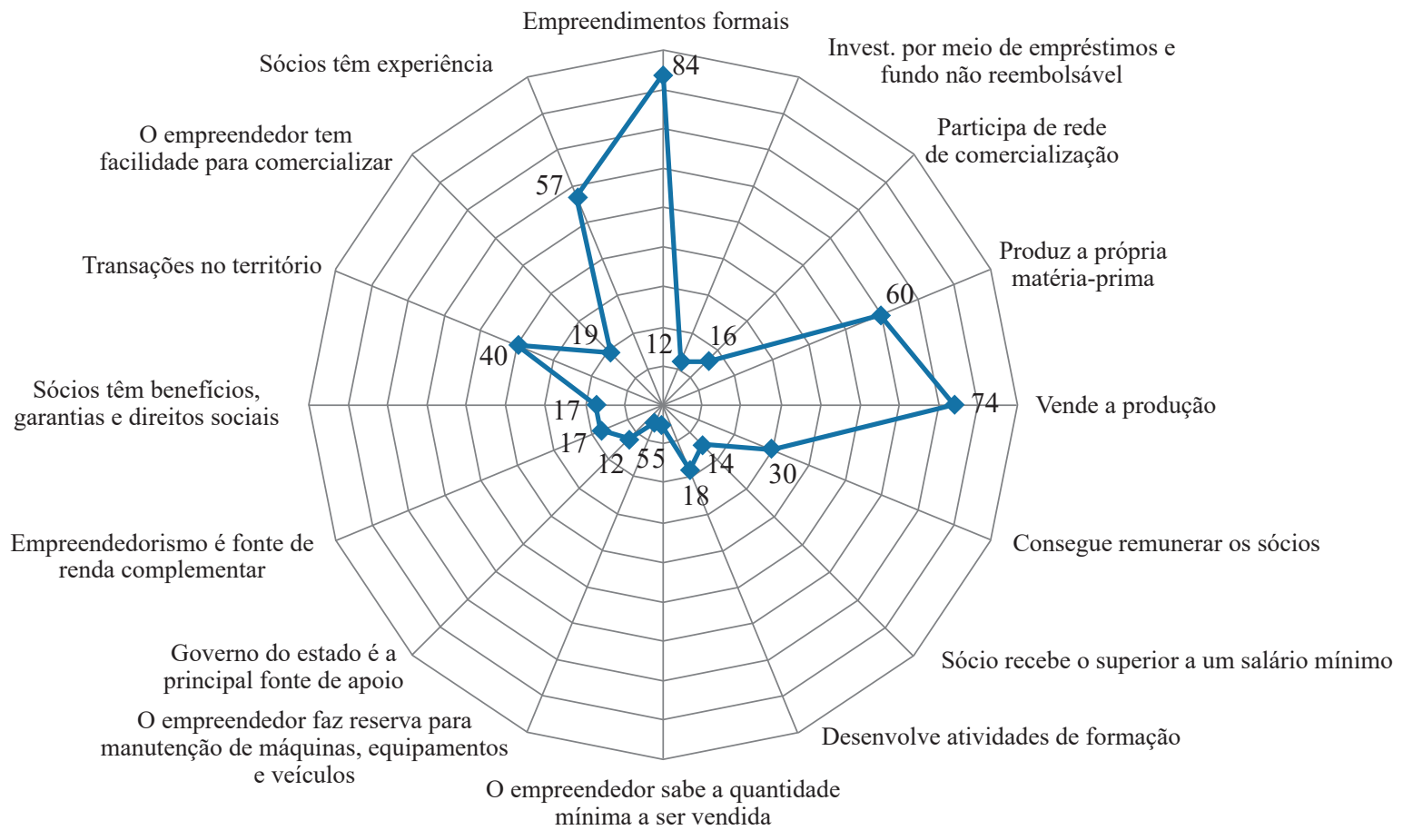

Fonte: Elaboração própria.

\section{CONCLUSÃO}

Com base em um conjunto de práticas derivadas das políticas públicas no TLS, foi possível provocar melhorias no ÍDH e no Índice de Gini de todas as cidades que o compõem, além de fortalecer o potencial endógeno do território na capacidade de promoção do próprio processo de desenvolvimento. Essas ações possibilitaram ainda a ampliação de dinâmicas socioprodutivas locais por meio de empreendimentos econômicos solidários, que impulsionaram as diversas formas de reprodução econômica e social, conforme observados nas tabelas 2 e 3 .

Por outro lado, são visíveis no TLS processos produtivos rudimentares, sem uso de modernas tecnologias e sem estarem integrados a unidades agroindustriais ou a algum centro de pesquisa, o que os impossibilita de gerar condições para um desenvolvimento sustentado, com condições de suplantar o baixo valor agregado dos produtos comercializados, conforme visto na Figura 5.

Isso pode ser entendido por meio da história da região do TLS, na qual a economia solidária tem sido conduzida de forma marginalizada e precária, tanto em termos jurídicos como econômicos e sociais, por conta da condição "coronelista" e "elitista" que povoa a região até os dias atuais.

Para alterar a realidade, é necessário um redirecionamento das políticas públicas de fomento, uma vez que os empreendimentos precisam buscar meios de sobreviver no mercado em que atuam por meio da inovação dos produtos, do processo produtivo e dos meios de comercialização. Esses elementos não são contraditórios conceitualmente com os princípios da economia solidária, pois possibilitam intensificar a ampliação da produtividade e de rendimentos. 
É preciso ainda persistir na formação de novos arranjos e dispositivos institucionais inovadores para que, por meio deles, seja possível o desenvolvimento de outra economia que valorize a diversificação da produção, realce os efeitos positivos na conservação do meio ambiente e sirva como um elemento estratégico para a formulação de uma agenda renovada em matéria de desenvolvimento territorial.

Para isso, é necessário uma mudança de paradigma de cunho técnico-econômico das iniciativas governamentais que possibilite aos empreendimentos do TLS inovações com agregação de valor não apenas na tecnologia, mas também no tecido social e econômico, permitindo que os indicadores de desenvolvimento humano continuem avançando de forma positiva. Isso inclui apoio ao desenvolvimento de novos produtos e processos, investimento nas atividades de penetração de novos mercados, como também a exploração de uma nova fonte de suprimentos e o estabelecimento de métodos organizacionais.

\section{REFERÊNCIAS}

AGUIAR, Paulo César Bahia de.; DE MOURA PIRES, Mônica. A região cacaueira do sul do estado da Bahia (Brasil): crise e transformação. Cuadernos de Geografía: Revista Colombiana de Geografía, v. 28, n. 1, p. 7, 2019.

ARAÚJO, Tânia Barcelar de. Dinâmica regional brasileira: rumo à desintegração competitiva? In: CASTRO, Iná Elias; MIRANDA, Mariana; EGLER, Claudio. (org.). Redescobrindo o Brasil: 500 anos depois. Rio de Janeiro: Bertrand Brasil/FAPERJ, 2000.

ATLAS do Desenvolvimento Humano no Brasil. 2013. Disponível em: http://www.atlasbrasil. org.br. Acesso em: 28 nov. 2019.

BAHIA. Secretaria do Planejamento. Plano de Desenvolvimento Territorial Sustentável Solidária. Salvador: Seplan, 2016.

Secretaria do Planejamento do Estado da Bahia. Territórios de Identidade do Estado da Bahia. 2018 Disponível em: http://www.seplan.ba.gov.br/modules/conteudo/conteudo. php?conteudo=17 Acesso em: 20 Abril. 2020.

Secretaria do Trabalho, Emprego, Renda e Esporte do Estado da Bahia. Sistema de Informação em Economia Solidária. Salvador: Setre, 2017.

- Superintendência de Estudos Econômicos e Estatística da Bahia. Perfil dos Territórios de Identidade da Bahia. 2015. Disponível em: http://www.sei.ba.gov.br/index. php?option=com_content\&view=article\&id=2000\&Itemid=28. Acesso em: 20 out. 2019.

BAIARDI, A.; TEIXEIRA, F. O desenvolvimento dos territórios do Baixo Sul e do Litoral Sul da Bahia: a rota da sustentabilidade, perspectivas e vicissitudes. Salvador: Escola de Administração da UFBA, 2010. Disponível em: http://www.observatorio.ufba.br/arquivos/ desenvolvimento.pdf. Acesso em: 30 set. 2019.

BCB - Banco Central do Brasil. Anuário Estatístico do Crédito Rural: 2012. Disponível em: http://www.bcb.gov.br/htms/creditorural/2012/pronaf.asp?idpai=RELRURAL2012. Acesso em: 8 out. 2017.

BECKER, Cláudio; ANJOS, Flávio S. dos Anjos; CALDAS, Nádia Veleda. Políticas públicas estruturantes e segurança alimentar: o caso do PAA. In: CONGRESSO DA SOCIEDADE BRASILEIRA DE ECONOMIA ADMINISTRAÇÃO E SOCIOLOGIA RURAL, 47., 2009, Porto Alegre. Anais [...] Porto Alegre, UFRGS, 2009. CD-ROM. 
BRASIL. Ministério da Economia. Secretaria de Trabalho. Economia solidária. 2015b. Disponível em: http://trabalho.gov.br/trabalhador-economia-solidaria. Acesso em: 26 nov. 2019.

BRASIL. Ministério da Economia. Secretaria de Trabalho. Economia solidária. 2015b. Disponível em: http://trabalho.gov.br/trabalhador-economia-solidaria. Acesso em: 26 nov. 2019

Ministério do Desenvolvimento Agrário. Secretaria de Desenvolvimento Territorial). Perfil Territorial: Território Litoral Sul da Bahia. Brasília: Secretaria de Desenvolvimento Territorial, 2015a. Disponível em: http://sit.mda.gov.br/download/caderno/caderno_ territorial_090_Litoral\%20Sul\%20-\%20BA.pdf. Acesso em: 10 abr. 2020

. Ministério do Desenvolvimento Agrário. Secretaria de Desenvolvimento Territorial.

Plano de Desenvolvimento Territorial Rural Sustentável. 2010. Disponível em: http://sit. mda.gov.br/download/ptdrs/ptdrs_qua_territorio090.pdf>. Acesso em: 10 abr. 2020.

Ministério do Desenvolvimento Sustentável. Programa de Aquisição de Alimentos. 2003. Disponível em: http://mds.gov.br/assuntos/seguranca-alimentar/programa-de-aquisicaodealimentos-paa/programa-de-aquisicao-de-alimentos. Acesso em: 8 nov. 2019.

CAMPOS, Telmara et al. Consumo, beneficiamento e comercialização de frutas no assentamento Terra Vista - Arataca-BA. In: CONGRESSO DE PESQUISADORES DE ECONOMIA SOLIDÁRIA, 2., 2018, São Carlos. Anais [...] São Carlos: Diagrama Editorial, 2018. Disponível em http://www.conpes.ufscar.br/anais-ii-conpes. Acesso em: 12 out. 2019

CEPLAC - Comissão Executiva do Plano da Lavoura Cacaueira. Premiados no Dia Internacional do Cacau destacam suporte técnico da Ceplac. Bahia, 2013. Disponível em: http://www.ceplac.gov.br/restrito/lerNoticia.asp?id=2095 Acesso em: 20 Abril. 2020.

CEPLAC - Comissão Executiva do Plano da Lavoura Cacaueira. Vassoura de Bruxa. Espírito Santo, 2017. Disponível em: http://www.ceplac.gov.br/radar/Vassoura de Bruxa.htm. Acesso em: 9 nov. 2019.

CERQUEIRA, Cristiane Aparecida de; JESUS, Clesio Marcelino de. O Território Litoral Sul. In: ORTEGA, Antonio C.; PIRES, Murilo J. de Souza. (org.). As políticas territoriais rurais e a articulação Governo Federal e Estadual: um estudo de caso da Bahia. Brasília: Ipea, 2016.

CHACON, S. Desenvolvimento. In: BOULLOSA, Rosana F. (org.). Dicionário para a formação em gestão social. Salvador: CIAGS/UFBA, 2014.

CHIAPETTI, Jorge. A crise da atividade cacaueira no contexto do reordenamento da economia mundial. Agrotrópica, v. 26, n. 3, p. 157-166, 2014.

CONAB - Companhia Nacional de Abastecimento. Transparência Pública do PAA - Programa de Aquisição de Alimentos. 2015. Disponível em: https://consultaweb.conab.gov.br/consultas/ consultatransparenciapaa.do?method=abrirConsulta, Acesso em: 20 Abril. 2020.

COSTA, Francisco Mendes. Políticas públicas e atores sociais na evolução da cacauicultura baiana. 2012. Tese (Doutorado em Ciências Sociais em Desenvolvimento, Agricultura e Sociedade) - Programa de Pós-Graduação de Ciências Sociais em Desenvolvimento, Agricultura e Sociedade, Universidade Federal Rural do Rio de Janeiro, Rio de Janeiro, 2012.

COUTO, Matheus Teixeira Pires do. Análise dos desafios socioambientais e papel da certificação na cacauicultura do Sul da Bahia. 2011. Dissertação (Mestrado em Ecologia) - Escola Superior de Conservação Ambiental e Sustentabilidade, Instituto de Pesquisas Ecológicas, Uruçuca, 2011. 
DATASUS - Departamento de Informática do Sistema Único de Saúde do Brasil. Índice de Gini da renda domiciliar per capita. 2010. Disponível em: http://tabnet.datasus.gov.br/tabdata/ livroidb/idb2010/b09.pdf. Acesso em: 18 dez. 2018.

DE MELLO SILVA, Sylvio Bandeira; SILVA, Barbara-Christine Nentwig. Estudos sobre globalização, território e Bahia. Universidade Federal da Bahia, 2003.

DESIGUALDADE SOCIAL. Índice de Gini. 2018. Disponível em: http://desigualdade-social. info/indice-de-gini.html. Acesso em: 5 dez. 2019.

OLIVEIRA BARRETO, R.; LOPES, F. T.; DE PAULA, A. P. P. A economia solidária na inclusão social de usuários de álcool e outras drogas: reflexões a partir da análise de experiências em Minas Gerais e São Paulo. Cadernos de Psicologia Social do Trabalho, v. 16, n. 1, p. 41-56, 2013.

DOWBOR, Ladislau. Que crise é esta?. Ponto-e-Vírgula, n. 17, 2015. Disponível em: https:// revistas.pucsp.br/pontoevirgula/article/view/25449. Acesso em: 27 maio 2020.

FONTES, M. J. V. Do cacau ao chocolate: trajetória, inovações e perspectivas das micro e pequenas agroindústrias de cacau/chocolate. 2013. Tese (Doutorado em Ciências Sociais em Desenvolvimento, Agricultura e Sociedade) - Programa de Pós-Graduação de Ciências Sociais em Desenvolvimento, Agricultura e Sociedade, Universidade Federal Rural do Rio de Janeiro, Rio de Janeiro, 2013

FUINI, Lucas Labigalini. A territorialização do desenvolvimento: construindo uma proposta metodológica. Interações, Campo Grande, v. 15, n. 1, p. 21-34, jan./jun. 2014.

GERHARDT, Tatiana Engel; SILVEIRA, Denise Tolfo. Métodos de pesquisa. Porto Alegre: Ed. da UFRGS, 2009.

GIL, Antonio Carlos. Métodos e técnicas de pesquisa social. 6. ed. São Paulo: Atlas, 2008.

GIOVANNINI, Michela. Solidarity economy and political mobilization: insights from Barcelona. Business Ethics: A European Review. abr. 2020. Disponível em: https://onlinelibrary.wiley. com/doi/abs/10.1111/beer.12283. Acesso em: 27 maio 2020

IBGE - Instituto Brasileiro de Geografia e Estatística. Censo Agropecuário 2006. Disponível em: http://ibge.gov.br. Acesso em: 29 nov. 2019.

IPEADATA - Base de dados do Instituto de Pesquisa Econômica Aplicada. Base de dados macroeconômicos. 2012. Disponível em: http://www.ipeadata.gov.br. Acesso em: 23 out. 2019.

LAKATOS, Eva Maria; MARCONI, Marina de Andrade. Fundamentos de metodologia científica. 5. ed. São Paulo: Atlas, 2003.

LEE. SUYEON. Role of the social and solidarity economy in locating sustainable development goals, International Journal of Sustainable Development \& World Ecology. v. 27, n. 1, p. 65-71. 24 set. 2019. Disponível em: https://www.tandfonline.com/doi/abs/10.1080/13504509.2 019.1670274. Acesso em: 28 maio 2020.

MIRA, Elson Cedro. Mudança institucional e reconversão produtiva no Sul da Bahia. 2013. Tese (Doutorado em Desenvolvimento, Agricultura e Sociedade) - Universidade Federal Rural de Rio de Janeiro, Rio de Janeiro, 2013.

MORAIS, Leandro Pereira. As políticas públicas de Economia Solidária (ESOL): avanços e limites para a inserção sociolaboral dos grupos-problema. 2013. Tese (Doutorado em Economia) - Universidade Estadual de Campinas, Campinas, 2013. 
MORAIS, Leandro Pereira; BACIC, Miguel Juan. A importância do ecossistema empreendedor para a economia social e solidária (ESS): avanços, retrocessos e desafios atuais no incunábulo do Brasil. Revista da Abet, Salvador, v. 18, p. 1-19, 2019. Disponível em: https://periodicos. ufpb.br/ojs/index.php/abet/article/view/38568. Acesso em: 27 maio 2020.

NEVES, Karina Fernanda Travagim Viturino. Formação territorial do sul da Bahia e produção não convencional do cacau. 2018. Tese (Doutorado em Geografia Humana) Universidade de São Paulo, São Paulo, 2018.

ORNSTEIN, Rudolf. Gráfico RADAR: uma forma alternativa de medir o desempenho econômico-financeiro. Porto Alegre, Revista do CRCRS, v. 18, n. 2-8, jul. 1989.

PERICO, Rafael Echeverri. Identidade e território no Brasil. Brasília: IICA, 2009.

PNUD BRASIL - Programa das Nações Unidas para o Desenvolvimento no Brasil. O que é IDH?. Disponível em: http://www.br.undp.org/content/brazil/pt/home/idh0.html. Acesso em: 16 nov. 2019.

PREZOTTO, Leomar Luiz. Qualidade ampla: referência para a pequena agroindústria rural inserida numa proposta de desenvolvimento regional descentralizado. In: LIMA, Dalmo M. de Albuquerque; WILKINSON, John. (org.). Inovações nas tradições da agricultura familiar. Brasília: CNPq/Paralelo 15, 2002. p. 285-300.

RANGEL, Maria Cristina; TONELLA, Celene. A crise da região cacaueira do sul da Bahia/ Brasil e a reconstrução da identidade dos cacauicultores em contexto de adversidades. Revista do Programa de Pós-Graduação em Geografia, Maringá, v. 5, p. 77-101, 2013.

REBOLLO, Mario Guilherme. O estudo de um método alternativo de demonstrar o desempenho econômico-financeiro de empresas industriais. 1991. Dissertação (Mestrado em Administração) - Programa de Pós-Graduação em Administração, Universidade Federal do Rio Grande do Sul, Porto Alegre, 1991.

ROCHA. M. O. Política de desenvolvimento territorial na Bahia: inovação e conservadorismo político. 2015. Dissertação (Mestrado em Planejamento Territorial) - Universidade Estadual de Feira de Santana, Feira de Santana, 2015.

RIBEIRO, P. S.; ROCHA, G. A. A.; SANTANA, A. S.; JESUS JÚNIOR, G. Participação da previdência na composição da renda do território de identidade litoral Sul da Bahia. Revista Observatorio de la Economía Latinoamericana, jun 2018. Disponível em: $<$ https://www.eumed. net/rev/oel/2018/06/previdencia-composicao-renda.html oel1806previdencia-composicao-renda>. Acesso em:12 Nov. 2018

SANTANA, Alessandro Fernandes de. Análise do Programa de Aquisição de Alimentos PAA como um vetor de fomento para a agricultura familiar no município de Ilhéus-BA: o caso da Coofasulba. 2013. Tese (Doutorado em Ciências Sociais). Programa de Pós-Graduação de Ciências Sociais em Desenvolvimento, Agricultura e Sociedade, Universidade Federal Rural do Rio de Janeiro, Rio de Janeiro, 2013.

SIDRA - Sistema IBGE de Recuperação Automática. Produção Agrícola Municipal (PAM). 2018. Disponível em: https://sidra.ibge.gov.br/pesquisa/pam/tabelas. Acesso em: 19 nov. 2019.

SILVA, Adriana Ferreira et al. Estrutura e renda da cadeia produtiva do cacau e chocolate no Brasil. Revista de Economia e Agronegócio, v. 15, n. 3, 2017. Disponível em: https:// periodicos.ufv.br/rea/article/view/7749. Acesso em: 27 maio 2020. 
. Cadeia produtiva do cacau e chocolate: perfil e desafios. Agropecuária, meio ambiente e desenvolvimento. In: CONGRESSO DA SOCIEDADE BRASILEIRA DE ECONOMIA, ADMINISTRAÇÃO E SOCIOLOGIA RURAL: AGROPECUÁRIA, MEIO AMBIENTE E DESENVOLVIMENTO, 53., 2015, João Pessoa. Anais [...] João Pessoa: Universidade Federal da Paraíba, 2015. Disponível em: http://www.sober.org.br/congresso. Acesso em: 14 nov. 2019.

SILVA, Sandro Pereira; CARNEIRO, Leandro Marcondes. Os novos dados do mapeamento de economia solidária no Brasil: apontamentos iniciais para o debate. Repositório Ipea, 2014. Disponível em: http://repositorio.ipea.gov.br/bitstream/11058/7410/1/RP_Os\%20Novos\%20 dados $\% 20$ do $\% 20$ mapeamento $\% 20 \mathrm{de} \% 20$ economia $\% 20$ solid $\% \mathrm{C} 3 \% \mathrm{~A} 1 \mathrm{ria} \% 20 \mathrm{no} \% 20$ Brasil_2016.pdf. Acesso em: 27 maio 2020.

UNCTAD - United Nations Conference on Trade and Development. Market Information in the commodities area. 2016. Disponível em: https:/unctad.org/en/PublicationsLibrary/ INFOCOMM_cp02_Cocoa_fr.pdf. Acesso em: 11 nov. 2019.

UTTING, Peter. Social and solidarity economy: beyond the margin. London: Zed Books, 2015.

Recebido em: 27/12/2019 Aceito para publicação em: 18/04/2020 